Marián Ambrozy, Július Krempaský, Olga A. Kalugina, Zhanna M. Sizova, Julia A. Krokbina and Michal Valío

\title{
Christianity and Information: Contributions of Ste- phen Hawking to Physics, Philosophical Ethics, and Theology
}

\author{
Krščanstvo in informacija: doprinos Stephena \\ Hawkinga na področju fizike, filozofske etike in teo- \\ logije
}

Abstract: Following the recent death of the famous physicist $\mathrm{S}$. Hawking, the question of his contribution to science has appeared with new urgency. Despite his known handicap, he was immensely active in the field of physics but also in the areas of philosophy and theology. The aim of the present paper is to analyze his contributions related to the nature of the Universe, its beginning and possible end, as well as the consequences stemming from this knowledge for philosophy and theology. We start with Hawking's discoveries in the fields of physics and cosmology and apply them to informatics. Subsequently, we extrapolate the acquired results to theology and philosophy, taking a closer look at issues of eschatology.

Key words: information, Stephen Hawking, theology, Universe, eschatology

Povžetek: Po nedavni smrti slavnega fizika S. Hawkinga se je z novo nujnostjo prebudilo vprašanje njegovega doprinosa $k$ znanosti. Kljub svoji splošno znani invalidnosti je bil izjemno dejaven na področju fizike, a tudi na področju filozofije in teologije. Cilj pričujočega članka je analizirati njegov doprinos predvsem $v$ razmerju do narave vesolja, njegovega začetka in morebitnega konca, obenem pa do posledic takšnega védenja za filozofijo in teologijo. Na začetku se posvečamo Hawkingovim odkritjem na področju fizike in kozmologije ter jih umeščamo v informatiko. Zatem dobljene ugotovitve prenašamo v teologijo in filozofijo, kjer se podrobneje posvetimo vprašanjem, ki zadevo eshatologijo.

Ključne besede: informacije, Stephen Hawking, teologija, vesolje, eshatologija 


\section{Introduction}

"At the beginning of the $20^{\text {th }}$ century, as a response to the state of scientific knowledge, the world of physics formulated two fundamental physical theories - the theory of relativity (special and general) and quantum theory which relatively adequately describe the micro-world, macro-world, and mega-world.« (Dubnička 2012, 558) Physicists such as Albert Einstein, Henri Poincaré, Max Planck, Niels Bohr, Erwin Schrödinger, Werner Heisenberg, etc., have played the most significant role in this endeavour. The development of physical science has not witnessed a radical change of paradigm since then (Karaba 2012, 519). The following generations of distinguished physicists, however, have also made important discoveries, adding interesting nuances to well-established theories (Andrade 2019). Stephen Hawking arguably belonged among the most incisive and creative ones.

The present paper attempts to show that Hawking's work represents an enormous contribution not only to physics itself but also to related natural sciences, as well as philosophy and theology. It should be emphasized, however, that as far as theology and philosophy are concerned, Hawking was not a revolutionary whose genius changed the elementary theses of these disciplines. He was a man who, for his own sake, too, tried to explicate some fundamental and existentially relevant ideas about reality correctly and usefully.

Hawking was not a physicist who founded a new physical discipline or added new physical theses that would radically change the existing physical models. Neither did he provide a new physical paradigm. Nevertheless, he became one of the most significant physicists of the last decades. "Hawking was highly regarded in the physics community and had been a minor celebrity to the general public even before his watershed book, appearing (for example) in Nigel Calder's UK television series The Key to the Universe in the late 1970s. " (Leane 2017, 29) His assertion that physics is currently taking over the role of philosophy and is trying to answer ever more philosophical questions made him famous, but it was met with considerable criticism. For example, Maco (2018) opines that such an approach is an exaggeration. Instead, Maco emphasizes that it is necessary to distinguish between the philosophy of science of a professional philosopher and that of a professional scientist (Maco 2018). Máhrik compares Hawking's standpoint with that of Kierkegaard. "While for Hawking philosophy is dead by the very character of the Universe, where man is just a quantum machine with no free will living in a world where there is no room for metaphysical reality, for Kierkegaard, philosophy is also dead, but this is because human aspirations and their existential aim exceed the realm offered by Philosophy. " (Máhrik 2014, 30) Harman (2012) compares philosophy to art, arguing against Hawking that »philosophy is no more dead than art « (22; Scott 2012). Heidegger $(1977,176)$ goes even further in his criticism, pointing out that physics itself cannot become an object of experiments. "Physics, as physics, can make no statements about physics. All the statements of physics speak in terms of physics. Physics itself is not a possible object of a physical experiment. « Despite the aforementioned contradictory comments, there are 
reasons to believe that physics provides much useful evidence as well as topics for numerous philosophical and theological questions. This assertion is linked to discoveries in the field of science made by Stephen Hawking.

Hawking himself was forced to principally change his opinions on several serious problems. These changes were, in fact, so significant that they earned him the Nobel Prize for physics. Unfortunately, Hawking did not get it, and he will never get it because it cannot be awarded posthumously. The range of Hawking's contributions was so vast that it is not possible to present all of them in one short paper. Our paper thus focuses only on three special areas of his research: (1) questions relating to the existence of God, (2) the origin and evolution of the Universe, and (3) the end of the Universe and all life in it. Hawking's well-known books, $A$ Brief History of Time, The Universe in a Nutshell, and his popular science book Black Holes, Baby Universe and Other Essays, provide a good overview of the above-mentioned areas.

\section{God in Hawking's work}

Researchers often quote the last sentence of chapter 8 of Hawking's popular science book, A Brief History of Time. The sentence asks if we still need God when we succeed in explaining the origin of the Universe. This sentence often leads to the conclusion that Hawking was an atheist. However, such a conclusion may be premature, at least at the time of Hawking's writing the book. It is also possible to use the last paragraph of the said book as a counterargument. In the said paragraph, Hawking states that the discovery of the holistic theory of everything would mean knowing the mind of God (Hawking 2008). Yet, there is another important statement that tends to be overlooked. In one of his numerous discussions, Hawking said that he did not need God as a creator but as an author of nature's omnipresent laws based on which also the Universe itself originated and evolved. This idea is like Thomas Aquinas' understanding of God and the role of Demiurge in Plato's Timaeus. Hawking really elaborated a special theory on the origin of the Universe without a need to postulate his famous Big Bang but at the price of making time into a fourth-dimension equivalent to the three spatial dimensions height, width, and depth. However, this can only be done by applying the so-called imaginary entity $\mathrm{i}=\mathrm{V}-1$, which shows that we are moving into a world different from our reality. "Real macrospace must be accompanied by the three dimensions; in every other physically possible case, life would not be feasible. " (Krob $1992,30)$ It is known that mathematicians and philosophers of mathematics do not perceive the ontological basis of complex numbers as trouble-free entities despite their immense usefulness. This is also why this topic is not often discussed. After all, there are more theories of the origin of the Universe which do not correspond to the inflation model, which is based on initial singularity. In the present cosmogonic paradigm, however, similar conclusions did not lead to questioning the starting points of the model, which is based on the Big Bang concept. "Obvi- 
ously, theology cannot competently decide what is in the beginning, if it is pure nothing (which is what the Big Bang idea leads to) or if it is the fluctuating vacuum as ,dirty' nothing or something chaotic without arranged structure which is more than both previous ,nothings'." (Trojan 1990, 7)

Science thus seems to indicate that divine natural laws are necessary not only for explaining the origin of the Universe but also for understanding its further development. The well-known, anthropic principle' claims that at the beginning of the evolution of the Universe, extremely delicate conditions had to be met to enable the evolution of life and human beings. "The anthropic idea was first introduced in 1961 by Robert Dicke, who noted the comparability of several very large numbers when fundamental physical constants are combined, and suggested that this might be connected with the conditions necessary for the presence of observers." (Stoeger 2007, 445) Let us mention the most important conditions.

It is a surprising scientific discovery that the scientifically proven Big Bang produced such amount of matter from the vacuum, which, as famous physicist $\mathrm{S}$. Weinberg says, was necessary for the origination of life and evolution of humans. Had it been any other amount of generated matter, life would most likely not have originated. It is thus a legitimate question if it was just a coincidence since, in this case, the possibilities were endless.

When a mechanism generates real matter from the vacuum, there is always the same amount of matter and the so-called antimatter. Their substance consists of particles or antiparticles. However, an encounter of matter and antimatter always results in their annihilation, which means that they vanish as particles, and what is left are only the particles of radiation, the so-called photons. The same situation occurred at the time of the Big Bang. One might thus ask why the Universe contains radiation as well as real matter from which everything originated. We know the answer, although we do not fully understand what happened. A little asymmetry occurred in the post-Big Bang matter - for every billion of antiparticles, a (billion +1 ) particles occurred. The above-mentioned annihilation led to the destruction of the particles and their transformation to radiation. There was just one particle left because it had no pair. And thanks to this redundant particle, we are here. Is it a coincidence?

Evolution processes after the Big Bang were directed by many, elementary constants.' They included mainly the amounts of matters and electric charge which the particles carried. Their amounts were precisely determined (by what? Or by whom?). If their amounts had been just a little different, there would have occurred no life in the Universe. The setting of amounts of quantities and constants is extremely precise. This topic is discussed in detail in the book A Fortunate Universe by G. F. Lewis and L. Barnes. The above-mentioned thoughts led to the use of the term fine-tuning and served as a basis for a philosophical concept called the anthropic principle. (Barrow and Tipler 1991) As Barrow and Tipler remind us, »Planck spoke of the existence of universal natural constants as a proof of the existence of physical reality independent of the human mind « (37). Einstein pre- 
sented a hypothesis relating to constants. He assumed that constants could be divided into two kinds. Apparent constants can be measured in particular units, for example, Boltzmann's radiation constant. Basic constants simply exist, and they are given. Their connection to unit systems is secondary. It is possible to express them non-dimensionally in proportions to other constants. For this, it is necessary to multiply them by constants that have a physical dimension. This way, it is possible to acquire genuine universal constants that are independent of the conventions of physicists. These constants are independent, and Einstein marked them with an asterisk. The ideas mentioned above led Einstein to the conclusion that God could not choose the constants freely (Barrow and Tipler 1991). Our feeling that possible worlds with other functional laws could exist means producing logically possible worlds that are not possible in the empirical sense of the word.

The debate about the fine-tuning principle has been lately brought to the boil by the discovery of the so-called dark matter, dark energy, and the Higgs boson. The existence of incomprehensible and precisely set compensations is the precondition for the smooth functioning of our world.

One of the significant messages of $\mathrm{S}$. Hawking was his advice to pay more attention to the evolution of the Universe than its creation. It is important to study the early history of the Universe. To put it simply, current science calls for the existence of ,the universe designer', which directs the evolution. Einstein expressed himself very clearly when he said that there had to be some form of limitless intelligence above it all. He also said that at the time of creation, God perhaps had no alternative regarding what the world was supposed to look like. Both philosophers and scientists assumed that the need for laws was embedded deeper. "Aristotle, Plato, Descartes, and later also Einstein believed that natural laws exist out of necessity, i.e., they are the only laws having logical meaning. " (Hawking and Mlodinow 2011, 41) Aristotle and his followers thought that natural laws could be deductively derived from logic. Physics would thus become a formal deductive science, and empiricism would be of secondary importance. According to Aristotle's methodology of science, experiment has only a demonstrative role (Posterior Analytics). Thinkers like Francis Bacon or Nicolaus Copernicus later changed this assertion. The rigid set of laws and conditions acquired a different, exclusively empirical character.

\section{Problems of Life}

Hawking's theories of black holes unexpectedly led to questions directly connected with the problems of life. Physicists, including Hawking, generally thought that when an object falls into a black hole, it ceases to exist, and so does any information relate to it. It means that it will never be possible to ,resurrect' this object. This theory was automatically applied to living creatures as well, i.e., the life of the creature and any information about it cease to exist in the black hole. 
This is thus ,the perfect death', after which there is nothing left in the Universe. However, surprisingly, thanks to Hawking, there has been a major shift in the opinion. The above-mentioned information about radiation from black holes is very important for informatics. ॥/f quantum gravity includes the holographic principle, it can mean that we can find out what is happening inside black holes." (Hawking and Penrose 2010, 49) After taking into consideration all aspects, Hawking reached the conclusion that an object in the black hole stops existing; however, the information remains. "Using standard ideas from quantum information theory, it was shown by Bekenstein that, in principle, the filtered Hawking radiation emitted by a $(3+1)$-dimensional Schwarzschild black hole may carry with it a substantial amount of information, the information which was suspected to be lost." (Hod 2018, 299) Hawking thus discovered a new natural law - the law of information conservation which has a significant impact on both philosophy and theology. Naturally, this new law exerts considerable influence on informatics, too. Hawking emphasized that "the loss of information would mean unitarity - a principle that the sum of all probabilities must be one " (Gleick 2011, 284). It is interesting that Hawking, having later discovered the way of information conservation in quantum gravity, had originally considered this principle invalid.

\subsection{Towards a new concept of information}

The concept of information becomes fundamental here. "The concept of information is gradually unfolded and is based on the different attitudes of informational theoreticians. A more thorough insight into exploration of the nature of information is provided by the fixation of several important assumptions." (Trejbal 2011, 2) There are numerous ways how to define information. There are about 23 different definitions of this word provided by informaticians and scientists from relating fields. We consider the following causalities relevant: "1. the concept of information somehow relates to entire reality; 2 . the concept of information is very close to some concepts used in philosophy or to multidisciplinary concepts connected with several scientific disciplines." (Stodola 2013, 112) There is a connection to epistemology, ontology, semantics, etc. As Stodola suggests, information is not only a multidisciplinary concept, but it is also transcendental in terms of ontology and epistemology. From our viewpoint, Frohmann (2004) goes too far when he suggests redefining - narrowing of the concept of information as well as its substitution by a different concept. He proposes to use the word document as a substitute for the concept of information. We do not agree with his proposal. In any case, information science is an open scientific discipline, and the philosophy of informatics also has something to say. We agree with Stodola's viewpoint $(2010,95)$ that no matter which of the standard definitions of informatics we adopt, it will not be possible to get rid of the transdisciplinary character of information science.

Scientists have defined informatics clearly, having also discovered a way to measure it. The units are called bits. "Bit is the amount of information which can determine which possibility from the variety of two equally probable possibilities ( $p$ ? 1/2) can become a reality. (Pavlik 2004, 9) All other facts about information 
can be found in The Information by J. Gleick (2011). The source of information is the person or machine which generates the message. "Message may be a sequence of characters, as in a telegraph or teletype, or may be expressed mathematically as functions - $f(x, y, t)$ - of time and other variables. " (Gleick 2011, 180) Shannon also tried to create the language of informatics. He used the calculation of physical stochastic processes. The stochastic process is neither predictable nor unpredictable. Shannon wanted to define the measure of information as a measure of vagueness (184). He introduced the measure of message uncertainty as message entropy. The term entropy was coined by physicist Rudolf Clausius. Shannon (1951) elaborated on the mathematical part of the theory of entropy. It is information where the bit unit is the smallest amount of information. Redundancy of natural languages varies. Some connections had been described by Norbert Wiener (1948) before Shannon. Wiener, who considered himself mainly a philosopher, believed that the human brain was a logical machine. Law on information conservation brings a completely new perspective on events connected with the life of a human being. On the one hand, death means the destruction of the human body, but the information about the person remains. In this respect, the human individual is an simmortal being. The fact is, however, that the information is perfectly scattered. This reminds us of the biblical dictum - you are dust and to dust you shall return (Gn 3:19). Naturally, one must ask a legitimate question - what can be done with information like that?

Information is basically any fact that can be expressed in a phrase or just a single word. To find a meaningful answer to the above question, we may turn to a simple example. Not long ago, a typical Christmas present for children was a box of cubes. On each cube, there was some sort of partial meaningless information. An intelligent person was able to arrange the cubes so that an originally scattered set of information changed to a meaningful picture, e.g., a castle, a scene from a fairy tale, or a portrait of a famous person. This way, it was possible to bring a profile from its non-existence (scattering of cubes) to its existence (arranging of cubes). According to the laws of thermodynamics, this requires non-zero energy. On the level of informatics, however, this energy is so small that it can be neglected. The problem of minimum energy necessary for computation was explained by famous Hungarian theoretician von Neumann (1981). His original calculation was adjusted by Landauer (2000) several decades later. Landauer's colleague Bennet (2003) continued studying the problem, proving that a large part of the computation process can be done without energy consumption, as the dispersion of heat causes deletion of information (Gleick 2011, 287).

The above-mentioned facts lead us to an interesting conclusion: an object can occur in the real world if the system of partial and scattered information about the object is logically arranged. There are reasons to believe that the same can apply to living objects having both physical and spiritual aspects. Some form of intelligence, however, must be present too. The intelligence of a human being should be sufficient in the realm of the non-living world. However, in the case of living creatures, the intelligence of a supernatural being - God is necessary. 
Consequently, it is necessary to ask if information needs a physical medium. What should we imagine under this physical medium? In the past, philosophers took a different approach to the concept of matter. One certainly cannot understand the concept of matter as all objective reality, as it was presented by Lenin in Materialism and Empirio-Criticism (1908). "In Lenin's book, the concept of matter is presented in noetic rather than ontological or metaphysical sense. Lenin uses the concept to name a givenness, a fact independent of consciousness, i.e., any reality regardless of its internal ontological structure or outward form." (Dieška 1996, 142) This bypassing of the ontological level was a mistake in Lenin's argumentation. He moved towards noetic realism. Such an understanding of materialism has no value in the ontological sense of the word. Information does not need a medium in the ontological sense of the concept of matter. Similarly, Sucharek asks: "What is thinking doing when it is thinking (about an idea)? What is thinking, and where is the idea? « $(2016,487)$

We want to answer the question if information needs a physical medium. Does it have physical nature? Trejbal thinks that the way informatics treats information is reductionist (Trejbal 2009, 9). Trejbal explains that information is grasped only from one aspect, and we do not have adequate conceptual tools to grasp it fully. With respect to thinking, reductionism as a method can be a double-edged sword. Trejbal also reminds us of Patočka's words that the concept of information does not solve any philosophical problem. In our opinion, a good definition of the concept of information can help a lot with respect to current as well as potential philosophical problems.

Pavlík looks at information from a different angle. He differentiates between subjective and objective understanding of entropy. In his opinion, the subjective approach considers information entropy a measure in arranging of symbols and not an entropy of physical systems. The said approach does not agree with the transformation of information into entropy $(2004,2)$. Pavlík states that the aforementioned understanding is influenced by Cartesian dualism. The objectivist approach tries to overcome dualism. In this case, "the original (Shannonian) communication context of the theory of information (where information has the role of an announcement or message) is abandoned and the term information is extrapolated to any (not only information) systems« (3). Those who do not perceive information through thermodynamic entropy, perceive the amount of information as arbitrarily defined sets of symbols, says Pavlík. He also emphasizes that Shannon's formula for quantification of information was derived with the help of Ashby's term of variety, which considers the combination of symbols in message transmission. Pavlík believes there is a connection between information and thermodynamic entropy with emphasis on the constant "W which in Boltzmann's equation $>S=k$. In $W$ c expresses thermodynamic probability (or degree of disorderliness), which can be interpreted also as Ashby's variety n« (17). This basically means that $\mathrm{W}=\mathrm{n}$. Pavlík states that this way, we get a relation $\mathrm{S}=\mathrm{k} \cdot \ln 2 \cdot \mathrm{H}=$ const. $\mathrm{H}$, or $(\Delta \mathrm{S}=$ const. $\Delta \mathrm{H})$ and similarly $\mathrm{H}=(\mathrm{k} \cdot \ln 2)-1 \cdot \mathrm{S}=1,11 \cdot 10^{23} \mathrm{~S}$. These relations can lead us to the Brillouin principle, which, as Pavlík points out, explains 
information as negative entropy. Another significant output of the connection between thermodynamic entropy and information is the possibility to evaluate the degree of physical orderliness (Krempaský 1982, 667).

In the above context, well-known Czech philosopher Patočka warns against metaphysical grasping of the concept of information because, in his opinion, it is an odd creation of idle metaphysics (1996). Structural connections from the dimension of semantics cannot be confused with the physical dimension. We agree with the above approach and the assertion that information as arbitrarily defined sets of symbols does not need a material medium. Simultaneously, we are aware of the existence of the relation between thermodynamic entropy and information. We are going to try to extrapolate these relations, which are so closely connected with Hawking's contribution to informatics, to selected problems of theology and philosophy.

\subsection{Information and philosophy/theology}

The above model of thinking helps us to gain a useful analogy (not an explanation) for several difficult philosophical and theological concepts and processes. Each information can be expressed in words. In this respect, we naturally remember the famous words of the Gospel of St. John (1:1): »In the beginning was the Word, and the Word was with God, and the Word was God." Clearly, one could conclude that in modern terminology, each word can be information as information can be verbalized.

We have already mentioned how to make it easier to understand the concept of immortality. People continue living as their information remains preserved also after their death. God is able, at any time He chooses, to turn this information into a ,spiritual' body that does not conform to any laws of physics. People who are alive cannot create such a ,spiritual' body from existing information; therefore, contact between celestial and terrestrial worlds is impossible. Contact between the two worlds would only be possible via limitless divine intelligence. This is not a case of classical Cartesian dualism. The above facts only seemingly remind us of the body-mind problem. The classical philosophical body-mind problem deals with the possibility of connecting the bodily and spiritual dimensions, and it includes celestial and terrestrial worlds. This topic requires further research.

It is very interesting to read also other parts of the Gospel of St. John (1:14): "And the Word became flesh, and dwelt among us. " This sentence is telling us that Jesus Christ, the second divine person, was born into this world in human body. John's idea can be rephrased stating that, divine information' got to a real human body and a ,divine person' was born. His essence consisted of a human body (man) and divine nature in the form of perfectly arranged, divine information'. The presence of the spiritual, divine nature in the human body means the presence of , divine information' in the body. Although the divine person remains a mystery to us, the said picture can help us understand the divine activity in him. It is a counterargument to Monophysicist views for which only the divine part of 
the Son is real. Monophysicists claim that the divine part has absorbed the human part. Then there is an opposing opinion of the Arians who believe that the Son was the first creation but not God in the direct sense of the word.

We know from the Scripture that Jesus acted as an ordinary man most of his life. He did not freely (i.e., arbitrarily) exercise his divine powers (for example, he had to turn around to see who touched him, he learned about the death of John the Baptist from other people two days after John's death, etc.). In certain moments, however, he manifested his divine nature and powers (transfiguration on the mountain, at performing miracles, etc.). In our analogy, (and with the help of the aforementioned example with cubes) we can imagine these ,transformations ${ }^{\prime}$ as the sudden transition from scattered divine information to the state of its perfect orderliness. While the information is there in both instances, it becomes visible, inteligible, and efficient only when ,ordered' in a certain way. The ordering of the intrinsic information, in Jesus' case, does not happen arbitrarily but always as a result of the Father's will and divine plan, as Jesus himself reminds his followers: "For I have come down from heaven not to do my will but to do the will of him who sent me." (Jn 6:38)

The above methodical approach can be useful in relation to the interpretation of the most important events connected with the suffering, death, and resurrection of Christ. Only after the body died, the divine essence seemed to return to Christ, and instead of his dead body, it gave him a 'glorified body which was not subject to natural laws (e.g., it ascended to Heaven). These phenomena caught the attention of American physicist F. J. Tipler $(2008,336)$, who tried to apply the regular laws of physics to these mysterious processes (chapter "The Resurrection of Jesus") in his book The Physics of Christianity. He concluded that if those laws had not been violated, the process of resurrection would have to be accompanied by an explosion, and this explosion would have destroyed the tomb as well as entire Jerusalem. How shall we deal with these questions?

Let us try to use the arguments of science without borrowing assumptions from metaphysics. It is a known fact that if processes take place on the information level, they do not require any consumption of energy. The energy corresponding to each information is immensely small. If we imagine the second divine person as a word, i.e., divine information, then it does not really matter what happened with Christ's dead body because this information can anytime generate a spiritual body' as a perfect substitute for the original mortal body. This approach to interpretation can satisfactorily explain two Biblical mysteries. (1) If not, all information was used during the said transformation, then the similarity probably is not absolutely perfect. Therefore, Mary Magdalene and Emmaus disciples did not recognize resurrected Christ at first sight. (2) The Bible does not provide any information regarding the resurrected Christ living somewhere or walking the Earth. His sudden appearance ,from nothing 'is thus an analogical transformation of scattered information to perfectly arranged information for the sake of the disciples to whom the resurrected Christ wished to appear. 
Such analogical way of thinking can be successfully applied also to the interpretation of the faith of humans after their death. All terms used in this field are strongly anthropomorphized, i.e., their content has been derived from real experience. The terms we refer to are immortality, eternity, bodily resurrection, heaven, hell, etc. Modern humans suspect that most of these conceptions of the afterlife may not be realistic. They would rather base their conceptions on scientific arguments. Our information approach may prove to be more intelligible and acceptable. As we have already mentioned, information does not disappear after death. We are well aware of the fact that people are ,dust' and to dust they shall return, which means that this seemingly indestructible information is perfectly scattered after the person's death. People are not able to transform this information into a form in which they existed on the Earth; therefore, any contact between the living and the dead is not empirically possible. Only God can do so. Based on the preserved information (guaranteed by the omniscient mind of God), He can generate a perfect ,new creation', a new original of a living subject. We may call this event resurrection, i.e., obtaining a non-physical body (via a new reordering of one's personal information) in which the subject can come to the Last Judgement. It is questionable, however, how to understand references about specific processes in Heaven or Hell, as these require time and time as we know it does not exist in a non-physical environment (so far as we, time-bound creatures, can tell). Salvation or damnation may thus depend on the fact if the resurrected subject can see God's face or not.

\subsection{Theology as scientia and the language of science}

It is clear that Christ did not tell everything to his disciples as it is written in the Gospel of John (16:12-13). „Christ could have told his disciples also other words; he could have continued explaining. However, he did not do it for their inability to embrace more knowledge." (Zozul'ak 2005, 205) As Zozul'ak points out, God's truth has no language, and theologians created a theological language for people to enable them to express this truth verbally. A theologian must be aware of the differences between the terms' meanings in created reality and non-created reality $(2005,209)$. God's essence itself is hidden, and the terms of theology are used for describing those aspects of God's facts, which people know. Gregory of Nyssa $(1954,584)$ emphasized that God's common essence, as the basis of God's hypostases, was not revealed and could not be described. The problem of expressibility thus relates to Trinitarian theology. As Gregory of Nazianzus $(1894,580)$ said, the language of theology can vaguely reflect the persons of the Trinity. However, it cannot touch God's essence. As Pružinský reminds us, »rational Eunomians claimed that they knew the essence of God. Saint Gregory was opposed to this belief, and he presented his own teaching claiming that there are limits to knowing God for both objective and subjective reasons $(2003,234)$. Saint Gregory spoke of finite pictures of God's reality. He also pointed at possible differing interpretations and valuations of theological terms that were in their real meaning present to those who had embraced God's truth (Zozul'ak 2005, 215). That time, 
however, did not witness defining theology as science. "We will have to wait for Abélard or for Thomas to constitute theology as science until Christianity finally accepts the term." (Marion 1996, 63) In any case, it is just an outline of reality, not a true expression of God's essence. The language of theology can change as Zozulak reminds us, and it is necessary to add that it should adapt to current knowledge of science. The differences between revealed theology and theologia naturalis were discussed by Thomas Aquinas. Some assertions of revealed theology have their parallels in theologia naturalis. For Aristotle, theologia naturalis was part of metaphysics. Christian Wolf claimed the same, although his language was more up to date. Metaphysics and natural sciences can overlap. In his metaphysical article Volek (2018) emphasizes that they both apply the same methods, methods of abstraction and idealization, a priori and a posteriori assertions and models. "Natural sciences use empirical testing, metaphysics uses rational explanation and, at the utmost, indirect empirical testing for proving if a metaphysical assertion is contrary to empirical theories." $(2018,354)$

Therefore, using analogical language and scientific terms (such as the term ,information') in trying to comprehend and describe the mysteries of creation and theology should not be considered a blasphemy but rather a humble attempt of those created in God's image to use the analytical and imaginative power of the human mind to understand oneself, the world, and its Creator better. Though Hawking could hardly be considered a theist, especially in the later stages of his life, his thought provides a window to understanding some of the deepest mysteries of our reality and our place in it.

\section{Conclusion}

The present paper analysed the contribution of physicist Stephen Hawking to natural sciences and humanities, whose impact can be felt beyond the area of natural sciences, namely in philosophy and theology. Our paper did not aim at showing that traditional Christian formulations concerning the afterlife should be abandoned and replaced by more modern formulations resulting from presentday science. These formulations are proclaimed truths marked by the fact that the spiritual world uses the language of the material world. This often brings us to the conclusion that we cannot understand things literally. For instance, Heaven and Hell should not be understood as two specific localities in the material space. Neither processes described orally or in written sources can be understood as real because the spiritual world knows no material processes. The idea that those saved in Heaven will constantly be looking at God's face and eternally singing songs to praise God should be taken as symbolic and metaphorical. The same applies to Hell and eternal life as such. In the end, human wisdom, including that of the best human science, must remain silent before the ineffable mysteries of God. Yet, we wish to propose that the transition from formalism based on material processes requiring energy to formalism based on the notion of information en- 
ables us to overcome some problems in using human language in the spiritual area. This does not mean, however, that one needs to give up employing the symbolic language used practically in the entire Bible. Wherever proper, it is rather useful to add certain matter-of-fact comments based on modern science, namely physics, for a more robust and up to date understanding our reality - and this was Hawking's great contribution.

In any case, the vast advances in science remind us of the changed role that theology and Christianity itself have come to play in the current, technologically developed, secularized world. In place of the tutelage role assumed by the church in the past (Žalec 2018) theology should rather understand »its mission in approaching the modern culture in the spirit of dialogue in order to open it to the truth of the gospel«, while ever searching for »truth, dialogue, hope, integrity, and connectedness" (Petkovšek 2019, 18). Only if theology keeps an engaged, committed, and competent approach to dialogue (Strahovnik 2017, 269) with the sciences and modern culture can it hope to remain faithful to its intrinsic purpose while remaining relevant as a partner and a culture-shaping force.

\section{References}

Andrade, Gabriel. 2019. Standing up for science against postmodernism and relativism. Philosophia (Philippines) 20, no. 2:197-211.

Barrow, John, and Frank Tipler. 1991. The anthropic cosmological principle. Oxford: Oxford University.

Benett, Charles. 2003. Quantum information: Qubits and quantum error correction. International journal of theoretical physics 42, no. 2:153-176.

Dieška, Jozef. 1996. The problem of noetic realism in Lenin's work materialism and empiriocriticism. Organon F 3, no. 2:141-180.

Dubnička, Ján. 2012. The quantum gravitation theory and its ontological basis. Filozofia 67, no. 7:557-569.

Dupkala, Rudolf. 2016. Conflict or dialog of cultures in the context of current migration. Philosophy and Canon Law 2:39-58.

Frohmann, Bernd. 2004. Documentation redux: Prolegomenon to (another) philosophy of information. Library trends 52, no. 3:387-407.

Gleick, James. 2011. The information: A history, a theory, a flood. New York: Pantheon Books.

Gregory of Nazianzus. 1894. Against the Arians, and concerning Himself. Nicene and post-Nicene Fathers: Second series 7. Buffalo: Christian Literature Publishing Co.

Gregory of Nyssa. 1954. Select writings and letters of Gregory, Bishop of Nyssa. A select library of
Nicene and Post-Nicene Fathers of the Christian Church 5. Eerdmans: Grand Rapids.

Harman, Graham. 2012. Concerning Stephen Hawking's claim. Filozofski vestnik 33, no. 2:11-22.

Hawking, Stephen. 1998. A short history of time. London: Bantam.

Hawking, Stephen, and Leonard Mlodinow. 2011. A briefer history of time. Trans. Vladimír Bužek. Bratislava: Slovart.

Hawking, Stephen, and Roger Penrose. 2010. The nature of space and time. Princeton: Princeton University Press.

Heidegger, Martin. 1977. Science and reflection. In: The question concerning technology and other essays, 155-182. New York; London: Garland Publishing.

Hod, Shahar. 2018. The Hawking paradox and the Bekenstein resolution in higher-dimensional spacetimes. Nuclear physics B, no. 933: 299305.

Karaba, Miroslav. 2017. Aplikácia vybraných vedeckých metodológií na otázky náboženského poznania. Filozofia 72, no. 3:192-203.

Krempaský, Július. 1982. Physics. Bratislava: SNTL.

Krob, Josef. 1992. Anthropical principle. Proceedings of the Faculty of Arts of the University of Brno 39:29-34.

Landauer, Rolf. 2000. Irreversibility and heat generation in the computing process. IBM 
journal of research and development 44, no. 1:261-269.

Leane, Elisabeth. 2017. Publishing: A brief history of Stephen Hawking. Nature 541, no. 7635:2829. https://doi.org/10.1038/nature16881.

Maco, Robert. 2018. Philosophy is dead: Long live physics! Filozofia 73, no. 4:269-281.

Máhrik, Tibor. 2015. The death and philosophy in Kierkegaard and Hawking. European journal of science and theology 11, no. 5:23-32.

Marion, Jean-Luc. 1996. On the Ego and on God. Paris: Presses Universitaires de France.

Patočka, Jan. 1996. The oldest Greek philosophy. Prague: Vyšehrad.

Pavlík, Jan. 2004. Information, ontology, entropy. E-logos 11, no. 1:1-22.

Petkovšek, Robert. 2019. Teologija pred izzivi sodobne antropološke krize: preambula apostolske konstitucije Veritatis Gaudium. Bogoslovni vestnik 79, no. 1:17-31.

Pružinský, Štefan. 2003. Patrology. Vol. 2. Prešov: Prešovská univerzita.

Rajabi, Mazdak. 2014. Critique of Malcolm's theory of religious beliefs: Are the groundless beliefs truly groundless? In: In the name of God: Proceedings the second international conference on contemporary philosophy of religion, 71-76. Tehran: Iranian Association for Philosophy of Religion

Scott, Callum. 2012. The death of philosophy: A response to Stephen Hawking. South African Journal 31, no. 2:384-404. https://doi.org/10.1 080/02580136.2012.10751783

Shannon, Claude. 1951. Prediction and entropy of printed English. Bell system technical journal 30, no. 1:50-64. https://doi. org/10.1002/j.1538-7305.1951.tb01366.x

Stodola, Jirí. 2010. Subject of information science and information education. Prolnflow 2, no. 2:87-105.

- - - 2013. The concept of information as an epistemological and methodological problem. Knižničná a informačná veda 24:99-118.

Stoeger, William. 2007. Are anthropic arguments, involving multiverses and beyond, legitimate? In: Bernard Carr, ed. Universe or Multiverse?, 445-457. Cambridge: Cambridge Press. https://doi.org/10.1017/ CB09781107050990.027

Storoška, Marek. 2018. The book of Genesis as foundation for the European civilisation's concept of social help. European journal of science and theology 14, no. 1:61-74.

Strahovnik, Vojko. 2017. Religija, javni prostor in zavzetost v dialogu. Bogoslovni vestnik 77, no. 2:269-278.
Sucharek, Pavol. 2016. A total image: Praise of thinking. Filozofia 71, no. 6:487-493.

Tipler, Frank. 2008. The physics of Christianity. New York: Image.

Trejbal, Pavel. 2009. Investigating the elusiveness of information. E-logos 16, no. 1:1-18.

Trojan, Jakub. 1990. Theology and economic practice and theory. Reflexe: Filosofický časopis 1 , no. 3:1-14

Volek, Peter. 2007. Analysis of the language of speaking about God (analogy) by Thomas Aquinas. In: Analogy in philosophy and theology, 107-117. Brno: Centrum pro studium demokracie a kultury.

Volek, Peter. 2018. Methods of metaphysics and natural sciences: On their similarities and differences. Filozofia 73, no. 5:345-355.

Von Neumann, John. 1981. The Principles of large-scale computing machines. Annals of the history of computing 3, no. 3:263-273. https:// doi.org/10.1109/MAHC.1981.10025

Wiener, Norbert. 1948. Time, communication and the nervous system. Annals of the New York Academy of Sciences 50, no. 4:197-220. https://doi.org/10.1111/j.1749-6632.1948. tb39853.x

Zozul'ak, Ján. 2005. Philosophy, theology, language. Prešov: Prešovská univerzita.

Žalec, Bojan. 2018. Verska strpnost in krščanstvo. Bogoslovni vestnik 78, no. 2:325-334. 